\title{
La imitación como estrategia de alfabetización visual en la formación del diseñador gráfico. Una propuesta metodológica desde el diseño editorial
}

\begin{abstract}
Resumen
El objetivo del presente artículo es analizar una propuesta educativa orientada al aprendizaje del lenguaje visual en diseño gráfico que recurre a la imitación como herramienta para mejorar la alfabetidad visual (entendida como la facultad para interpretar y construir imágenes o la capacidad para comunicarse eficazmente mediante códigos visuales). La investigación emplea una metodología cualitativa de observación participativa basada en un estudio de caso - la asignatura Comunicación Visual, perteneciente al grado universitario en Periodismo, durante el período 2019-2021 - para evaluar el desarrollo de dos publicaciones de la especialidad de diseño editorial (revista y libro), siguiendo la técnica del Aprendizaje Basado en Proyectos. Los resultados, atendiendo a la excelencia de los trabajos y al óptimo rendimiento académico, avalan la utilidad de la copia y de las herramientas digitales para la inspiración (Pinterest) en la alfabetización visual de los alumnos. Las conclusiones apuntan al especial interés de este método en la formación del diseñador gráfico, principalmente en las fases de enseñanza más tempranas y en aquellas materias centradas en el aprendizaje del código visual; a la positiva repercusión de la copia en la comprensión de los aspectos comunicativos del diseño gráfico; $y$, finalmente, a la importancia del software de autoedición en el dominio de los conceptos básicos del lenguaje visual (la tipografía, el color y la composición, fundamentalmente).
\end{abstract}

\author{
Fernando Suárez-Carballo \\ Doctor en Comunicación. \\ Universidad Pontificia de Salamanca, \\ Salamanca, España. \\ Correo electrónico: fsuarezca@upsa.es \\ () orcid.org/0000-0001-7498-6595 \\ Google Scholar \\ Juan-Ramón \\ Martín-Sanromán \\ Doctor en Comunicación. \\ Universidad Pontificia de Salamanca, \\ Salamanca, España. \\ Correo electrónico: jrmartinsa@upsa.es \\ ๑ orcid.org/0000-0003-1998-4591 \\ Google Scholar \\ Nuno Martins \\ Doctor en Medios Digitales. \\ Instituto Politécnico do Cávado e do \\ Ave, Barcelos, Portugal. \\ Correo electrónico: nmartins@ipca.pt \\ 이 orcid.org/0000-0002-5228-5453 \\ Google Scholar
}

Recibido: marzo 18 de 2021 Aprobado: agosto 19 de 2021

Palabras clave:

alfabetidad visual, diseño editorial, diseño gráfico, formación, imitación. 


\section{Imitation as a visual literacy strategy in the training of graphic designers. A methodological proposal from the editorial design}

\begin{abstract}
The objective of this article is to analyze an educational proposal aimed at learning visual language in graphic design that uses imitation as a tool to improve visual literacy (understood as the ability to interpret and create images or the ability to communicate effectively through visual codes). The research uses a qualitative method of participatory observation based on a case study the subject Visual Communication, belonging to the university degree in Journalism, in the period 2019-2021 - to evaluate the development of two publications of the specialty of editorial design (magazine and book) following the Project-Based Learning technique. The results, according to the excellence of the works and the remarkable academic performance, reveal the usefulness of copying and the digital tools for inspiration (Pinterest) in the visual literacy of the students. The conclusions point at the special interest of this method in the training of graphic designers, mainly in the earliest learning stages and in those subjects focused on the visual code, at the positive repercussion of the copy in understanding the communicative aspects of graphic design and, finally, at the importance of desktop publishing software in the management of the basic concepts of visual language (mainly typography, color and composition).
\end{abstract}

Key words:

editorial design, graphic design, training, imitation. 


\section{Introducción}

El concepto de "alfabetidad visual" se refiere a la aptitud de los agentes comunicativos para interpretar y producir mensajes visuales o "la habilidad de comunicarse mediante los códigos visuales, aprendidos y enseñados desde su nacimiento" (Peltzer, 1991, p. 29). Concebida como el conjunto de competencias que los individuos desarrollan en la observación de su entorno y empleada habitualmente como sinónimo de cultura visual, esta alfabetidad permite identificar e interpretar una amplia tipología de imágenes: las acciones visibles, los objetos y los símbolos (naturales o artificiales) son algunos ejemplos (López y Villa, 2017). Díaz (1993) habla de "autocensura interna" cuando la carencia de esta alfabetización visual conduce a una percepción "estereotipada, mimética y simplista", muy restrictiva, que únicamente atiende a lo "inmediato" (p. 47), unas deficiencias que pueden ser subsanadas mediante un aprendizaje visual que permita al individuo (emisor y receptor) una mejor construcción y lectura de los mensajes visuales. En definitiva, como sostienen Aparici y García-Matilla (1998), la alfabetidad visual implica la capacidad de comprender y expresarse eficazmente a través de los elementos visuales:

A un individuo no podemos considerarlo alfabetizado en tanto no realice la doble articulación de descodificar (leer) y codificar (expresarse) a través de signos de naturaleza diferente a los escritos, así como lograr que esos signos puedan ser usados (transferidos) en diferentes situaciones y áreas de conocimiento del proceso de enseñanza-aprendizaje y de la realidad cotidiana. (p. 9)

Kędra y Žakevičiūtè (2019) aluden al carácter multidisciplinar de la alfabetidad visual, que reúne tres categorías de destrezas: la lectura visual, que abarca competencias como la interpretación y análisis de imágenes, la evaluación y percepción visual, el conocimiento de la gramática y la sintaxis visuales y la capacidad de traducción visual-verbal; la escritura visual, que incluye habilidades de creación gráfica, de producción y uso de imágenes y de comunicación visual eficaz; y, por último, otras facultades ligadas a la 
comunicación gráfica, como el pensamiento visual, destrezas de aprendizaje y el uso de la imagen en determinadas situaciones (el aspecto ético, por ejemplo).

En este sentido, como sostiene Suárez-Carballo (2008), la alfabetidad visual comporta la existencia de un lenguaje visual, que es posible diseccionar y analizar, y de una sintaxis integrada por partes constitutivas básicas y reglas de coordinación, aceptadas y reconocidas por emisores y receptores, similar a la propuesta por la lingüística. Como se pregunta Dondis (1998) sobre esta analogía, "si un medio de comunicación es tan fácil de descomponer en elementos y estructuras, ¿por qué no va a serlo el otro?" (p. 21). En el ámbito educativo, sin embargo, se ha observado tradicionalmente una desventaja entre la alfabetidad textual y la alfabetidad visual, que ha sido desplazada del aula por la primera y que compromete la correcta comprensión del mensaje gráfico. Por tanto, en un entorno saturado de estímulos (no solo visuales), un mayor peso de la imagen en la formación se interpreta como una necesidad primordial para "comprender los contenidos inherentes a los constructos que configuran la iconosfera, responsabilidad compartida por las áreas de saber que se desarrollan en torno de la imagen" (López y Villa, 2017, p. 180).

Dentro de los límites de la alfabetidad visual se sitúa la alfabetidad en diseño, considerada igualmente una competencia tanto del diseñador profesional como del público en general, en su calidad de ciudadanos y participantes en la toma de decisiones de procesos de innovación social (Bastías, 2020); frente a las habilidades básicas que se asignan al usuario menos avezado, al diseñador experto se le exigen destrezas más avanzadas, centradas en el dominio del lenguaje visual: de la tipografía, del color y, en general, de todos los recursos sintácticos que configuran su código. En la formación de los profesionales del diseño gráfico, concretamente, como una especialidad del diseño en la que la comunicación se erige como su misión principal, "dominar y corregir la forma y el color, reconocer la tipografía apropiada y encontrar el tono que 
necesita la pieza gráfica en cuestión" (Fontana, 2019, p. 73), son algunas de las facultades que deben adquirir los egresados en esta disciplina para atender a los requerimientos de la profesión:

\footnotetext{
Los actuales perfiles profesionales que demandan las empresas de comunicación cada vez buscan más personas integrales con conocimientos y habilidades para poder diseñar y proyectar productos de consumo, en donde los conocimientos estéticos, de composición, tipografía y color son imprescindibles. (Jiménez-Narros, 2016, p. 275)
}

Frente a las anteriores aportaciones y atendiendo a estas necesidades, Valdés de León (2012) sugiere desterrar definitivamente el concepto de "alfabetidad visual" del ámbito del diseño gráfico y sustituirlo por un concepto más amplio "que incorpore la noción de Semiosis en el marco de una Cultura Visual integradora, en un proceso de Enseñanza/Aprendizaje del Diseño cuyos objetivos serían capacitar al estudiante para que pueda ejercer razonablemente la profesión de comunicador visual" (p. 62). En cualquier caso, más allá de este debate, proporcionar herramientas para la mejora de las habilidades visuales constituye uno de los retos esenciales en la formación del diseñador gráfico.

\section{El dominio del lenguaje visual como competencia del diseñador gráfico}

El diseño comparte con otras disciplinas visuales, como las artes aplicadas, "el código gráfico como un sistema operativo básico: el manejo específico de modelos sintácticos y retóricos es el máximo nivel de abstracción obtenido por la disciplina" (Arfuch et al., 1997, p. 131); su principal peculiaridad, en cambio, apunta a la utilidad, funcionalidad o la especial dimensión comunicacional, que exigen una importante labor conceptual a la que se supedita toda decisión configurativa. En este sentido, Abdulla (2021) critica el excesivo protagonismo en el diseño de cuestiones exclusivamente estilísticas frente a las tareas de carácter intelectual y González-Díez et al. (2018) insisten en la relevancia 
de la reflexión como esencia del diseño, antes que los procedimientos de materialización formal.

El peso indiscutible de las tareas intelectuales no debería conducir, sin embargo, a menospreciar la trascendencia del plano visual como sustancia expresiva del mensaje, de la misma forma que la disociación de Diseño — también en su concepción estética — e Información —el plano del contenido—, en el afán de potenciar la eficacia comunicativa, resulta inviable (Gamonal et al., 2020); en algunos campos, como el periodístico, este nexo es particularmente evidente. Sin embargo, como sostiene Contreras (2019), el carácter funcional del objeto de diseño ha obstaculizado tradicionalmente la apreciación de su valor estético; por ello, un conocimiento que integre el proceso de comunicación, los recursos de producción y los elementos gráficos que intervienen en los mensajes debe ser una competencia ineludible en la formación integral del diseñador (Tena, 2004).

Dentro del vasto campo del diseño gráfico, el diseño editorial es el área encargada de la confección visual de libros, periódicos, revistas y otro tipo de publicaciones (Campi, 2020), que difieren entre sí en cuestiones de periodicidad, objetivos (informativo o persuasivo) o soportes (impreso o electrónico), y que utiliza como sustancia básica las series lingüísticas, no lingüísticas y paralingüísticas de Verón (Puebla-Martínez et al., 2018); atendiendo a esta división, en resumen, "la imagen y la palabra escrita son el medio del que se vale para significar y resignificar la realidad simbolizante" (Mazzeo, 2017, p. 25). En esta especialidad, el lazo entre el diseño y el contenido, entre la forma y la función, es especialmente sensible y debe ser tenido en cuenta en el ámbito educativo. 


\section{La formación del diseñador gráfico: conocimientos y destrezas}

En la formación en diseño gráfico, como disciplina de carácter proyectual (González-Mardones, 2016), conviven dos modelos de enseñanza complementarios: la enseñanza de un saber para hacer, relativa a una serie de conocimientos que permite desenvolverse con solvencia en el ejercicio profesional, y la enseñanza de un hacer, un "desarrollo de trabajos que, en muchos casos, reproducen los que pueden tener que realizarse en la práctica profesional de la disciplina" (Mazzeo, 2015, p. 216). Entre los métodos docentes más populares en esta última opción, sobresale la metodología del Aprendizaje Basado en Proyectos (ABP), una técnica que, partiendo de orientaciones concretas por parte del profesor, procura un rol especialmente activo de unos estudiantes que, de esta manera, "aprenden haciendo" mediante la solución de problemas (Rodríguez-Sandoval et al., 2010). Se trata, por tanto, no solo de aprender acerca de algo, sino también de "hacer algo" (Jiménez-Narros, 2016).

Bridges (2020) menciona tres áreas de conocimiento fundamentales en los programas de diseño deeducación superior: habilidades actuales dealfabetización digital, conocimiento de las tendencias en comunicación digital y principios del diseño. Por su parte, Mazzeo (2015) identifica los contenidos imprescindibles de estos programas, a saber: los objetivos formales (sobre los atributos sensibles de la imagen, su producción y organización); la dimensión comunicacional (vinculada a campos como la lingüística, la semiótica y la retórica); factores disciplinares (relativos a las particularidades de la especialidad de diseño gráfico en la que se inscriben); o aspectos metodológicos, que se refieren al propio proceso de diseño. Finalmente, en un nivel mayor de concreción, Frascara (2018) apunta, entre las competencias específicas del futuro diseñador, a la atención a los detalles; la capacidad para buscar, encontrar, recopilar y organizar información; la facultad de ver y evaluar productos y sistemas; el conocimiento de los sistemas de producción; eficiencia y claridad; percepción visual; factores 
culturales o la relevancia de la investigación en el proceso creativo; y, finalmente, la sofisticación visual y la sensibilidad para los materiales.

El dominio del lenguaje visual en la formación en diseño gráfico, recogida en las anteriores aportaciones, comparte con los aspectos tecnológicos su relevancia en la confección del mensaje. Pese a que Heller y Anderson (2016) sostienen que "el gran diseñador es aquel cuya imaginación trasciende (las) herramientas a fin de crear oportunidades de innovación” (p. 6), Cerezo (2017) afirma que existe una suerte de condicionamiento mutuo entre tecnología y concepto, herramienta y estilo, cuya combinación indivisible da lugar al artefacto gráfico. En la misma línea, Entenza et al. (2015) subrayan que los conocimientos técnicos inciden directamente en los procesos configurativos del mensaje, al potenciar la creatividad y contribuir a la gestación de mejores ideas, más allá de su simple intervención en la producción del mensaje.

Las anteriores reflexiones sugieren que es la formación multidisciplinar del diseñador gráfico (técnica, comunicacional, cultural, estética) la que le permitirá ofrecer soluciones óptimas a los problemas que plantee cada encargo. El conocimiento del lenguaje visual y las destrezas técnicas, por tanto, se antojan como una exigencia imprescindible en su futuro profesional.

Además de las fuentes mencionadas, la literatura científica ofrece un abundante repertorio de referencias sobre la pedagogía del diseño gráfico, con una amplia variedad de enfoques: centrados en la transversalidad e interdisciplinariedad en la formación del diseñador (Presol-Herrero y PérezManzanares, 2020; Morales y González, 2021) o en la construcción del discurso visual mediante la retórica (Gamonal, 2012), por citar solo algunos ejemplos destacados, si bien no presentan modelos concretos de aprendizaje del lenguaje gráfico. Al mismo tiempo, numerosas investigaciones profundizan en la alfabetización visual en el contexto educativo, recogiendo 
experiencias formativas que se refieren al consumo y análisis de imágenes desde una perspectiva cultural o ideológica (Tavin, 2009) o efectuando una revisión de las prácticas que definen la alfabetidad visual en la educación superior (Kędra, 2018), pero no plantean fórmulas de enseñanza en el ámbito específico del diseño gráfico. Otros proyectos sí sugieren acciones concretas de alfabetización visual en esta área, con una orientación crítica y conceptual, a través de la fotografía (López y Villa, 2017), o, en la propuesta de Ortega (2011), mediante un completo aparato didáctico de lectura de textos visuales publicitarios (estáticos, audiovisuales o multimedia) que añade al plano morfosintáctico otros niveles (semántico, crítico y emotivo) pero que olvida la tipografía como componente de singular trascendencia para la alfabetidad en diseño gráfico.

\section{Inspiración, imitación y copia como recursos de aprendizaje}

Numerosos autores aluden a la relevancia de la fase de investigación en la metodología de aprendizaje; para Shaughnessy (2006), por ejemplo, el conocimiento cultural, que implica "la observación, estudio y absorción constante" del mundo (p. 19), es fundamental para obtener soluciones exitosas; en un sentido similar, Frascara (2018) sostiene que "el pensamiento y el hacer se alimentan de la observación, el análisis y la crítica" (p. 36). Entre los factores sensibles que están involucrados en esta fase de investigación, Knight y Glaser (2010) apuntan a la jerarquía visual; el uso de los elementos gráficos de identidad; el tratamiento, encuadre y escala de las imágenes; la legibilidad de los textos o el formato, el papel y el tipo de encuadernación. El diseñador Chris Bolton, por ejemplo, admite con naturalidad integrar estos métodos en sus protocolos creativos:

Creo listas con innumerables ideas, tomando prestadas algunas imágenes de los diseñadores y artistas cuyas obras admiro. Este proceso estimula mi mente a establecer varios enfoques e ideas. Creo que es algo natural aprovecharse de las ideas de otros artistas. Al fin y al cabo, el arte de calidad es el resultado de todo cuanto le ha precedido. (En Millman, 2009, p. 196) 
En relación con las bondades de esos métodos exploratorios en el proceso creativo, la inspiración ocupa un lugar primordial: Zeegen (2013) alude a la relevancia de la fase de observación y la búsqueda de materiales de referencia y recursos, un proceso que también defiende White (2014), al sugerir que, por cada hora de creación, debe dedicarse otra a la reflexión y la observación. En una postura más radical, vinculada a esta misma fase de inspiración, varios autores reivindican la utilidad de la copia en la formación en diseño gráfico; siguiendo este proceso, la imitación de referentes constituiría un método eficaz para alcanzar una voz propia, que resulta, a su vez, de la dificultad de reproducir estrictamente la construcción original (Kleon, 2012; Fontana, 2019):

La copia, tan denostada en nuestra sociedad, es una de las partes esenciales de muchos procesos creativos. Ante la duda, las referencias e inspiraciones son cruciales. Y eso no quiere decir, en realidad, que calques un proyecto que te gusta, sino que puedas apreciar qué lo hace diferente y qué te interesa de él; y lo puedas aplicar al problema que debes resolver de forma que lo acabes convirtiendo en otra cosa distinta. (Gràffica, 2020, p. 125)

Como sugieren Suárez-Carballo y Muñiz-Velázquez (2008), la creatividad deriva del empleo de un rico — aunque finito — catálogo de ingredientes visuales y de la apropiación selectiva de recursos gráficos, preferiblemente de aquellas especialidades más lejanas: es su combinación en un nuevo contexto, junto con el bagaje cultural adquirido por el diseñador, lo que proporciona la novedad. En palabras de estos autores, la copia de las fases iniciales conduce a la inspiración y esta, en un progresivo proceso de asimilación de referencias, a la creatividad. Atendiendo, en esta línea, a la máxima de Voltaire — "la originalidad no es otra cosa que imitación con criterio" (Gràffica, 2016b, p. 43)—, esta fórmula parece una interesante opción para ejercitar la imaginación y alcanzar la innovación mediante su reutilización en un nuevo proyecto: 
No la copia sino la "imitación" de un elemento (objeto o acción) existente precedentemente (natural o, más a menudo, artificial) sirve al diseñador (...) para realizar otro que destinará (aunque a veces no lo parezca) a una nueva prestación (otra forma de ejercitar la función), sin embargo el conocimiento del primero le ha facilitado sustancialmente la tarea. (Rambla, 2007, p. 78)

Un gran número de autores y diseñadores gráficos respalda esta metodología no solo en el contexto académico sino también en el ejercicio profesional: para Lessig (2016, p. 31), muchos diseñadores expertos recurren a la tecnología para reciclar el contenido ajeno y decir las cosas de forma diferente. En esta línea, copiar no significaría calcar sino comprender las referencias utilizadas y trasladarlas a una nueva tarea, con una evolución conceptual y formal resultante de un exhaustivo proceso de investigación que, como defiende el diseñador Claret Serrahima, incluye conocer la historia del diseño y convivir con la cultura previamente a la formalización (Gràffica, 2016a, p. 64). Se trataría, por tanto, de una práctica cotidiana, consolidada y perfectamente legítima cuando es sinónimo de influencia de determinados modelos de referencia (Guerra, en Gràffica, 2016b).

Finalmente, entre los trabajos científicos vinculados al presente apartado, en concreto, cabe destacar de forma especial el estudio de Suárez-Carballo et al. (2021), que, entre otras conclusiones, defiende la relevancia de la copia en la educación estética de los estudiantes, atendiendo a las impresiones de los docentes responsables de las materias de dirección de arte de los grados españoles de Publicidad.

\section{El valor de las herramientas digitales en la inspiración}

En el ámbito educativo, desde hace años se viene destacando el potencial de las Tecnologías de la Información y las Comunicaciones (TIC) en las estrategias académicas y la positiva valoración como recurso didáctico por parte del alumnado (Colás-Bravo et al., 2015; Cabero-Almerara et al., 2019). 
Dentro de estas prácticas, pese a las diferencias en su implementación y a la falta de consenso sobre las competencias necesarias (Barba y Palacios, 2018), las redes sociales han adquirido un papel especial, al aprovechar "tanto los nuevos hábitos de los estudiantes, que pueden ver el uso de estas aplicaciones como una prolongación de sus rutinas sociales, como la participación activa en el proceso de aprendizaje" (Gómez et al., 2018, p. 276).

En relación con estos recursos de aprendizaje en una sociedad actual marcada por la cultura de la imagen (De la Flor, 2009; Danesi, 2017), sobresale el uso de Pinterest, una red social de marcado carácter visual que permite la recopilación y organización de imágenes mediante tableros. Pese a que la interacción de los usuarios es más débil que en otras plataformas, dado que no busca generar relaciones directas, se trata de un servicio de bookmarking con gran potencial para los aspectos visuales de la enseñanza, al almacenar y compartir imágenes que puedan servir como ejemplo o inspirar al estudiante (Gómez et al., 2018).

El estudio desarrollado por Suárez-Carballo (2020) concluye que, en la actualidad, las TIC tienen una amplia presencia en el planteamiento de las asignaturas de diseño gráfico en los grados universitarios de España, en este caso vinculados a la Publicidad. Entre las herramientas más utilizadas, destacan los servicios de blogging (como Tumblr) y, muy especialmente, de marcadores de imágenes, como el citado Pinterest. El estudio revela asimismo la atención, aunque menos habitual, de otros recursos digitales en la impartición de estas materias, como plataformas para la promoción del alumno (Behance), de marcadores genéricos, de visualización de publicaciones de naturaleza impresa en pantalla (Issuu) o de Instagram, una red social de naturaleza esencialmente visual que permite estimular la imaginación, las ideas y la productividad de los estudiantes de diseño gráfico (Salehudin et al., 2020). 


\section{Método}

Inspirado en el trabajo de Ramírez (2020), esta investigación acude, a partir de la anterior revisión bibliográfica, a una técnica cualitativa de observación participativa basada en un estudio de caso - la experiencia en la asignatura Comunicación Visual, del grado universitario en Periodismo, durante dos cursos académicos (2019-2021) — para describir una propuesta metodológica basada en la imitación como técnica principal para el aprendizaje del lenguaje visual en el ámbito del diseño editorial (como especialidad del diseño gráfico).

\section{Descripción de la asignatura Comunicación Visual}

La asignatura Comunicación visual está ubicada en el primer curso de la titulación de Periodismo de la Facultad de Comunicación de la Universidad Pontificia de Salamanca. Integrada en el módulo de Producción Informativa de la titulación, su descriptor hace hincapié en el aprendizaje de los fundamentos visuales del lenguaje visual para la correcta comunicación del mensaje:

Conocimiento de los fundamentos de la Comunicación Visual, así como de sus diversas estrategias y códigos en función de la intención comunicativa. Incluye el análisis de los fundamentos de la tipografía, la forma, el color y la composición, y está enfocada al desarrollo de la capacidad de expresión visual y de la presentación correcta del mensaje (ya sean documentos escritos o digitales), de modo que se ayude a estructurar y mejorar la comprensión de los textos y a emplear una estética que refuerce su discurso. (Universidad Pontificia de Salamanca, 2020)

Partiendo de este descriptor, la asignatura plantea los siguientes objetivos, que refuerzan la filosofía mencionada: comprender y adquirir los principios básicos de la comunicación visual y el diseño gráfico; reflexionar sobre las posibilidades de la imagen en la transmisión del mensaje; crear y gestionar proyectos gráficos a partir de los fundamentos teóricos y mediante la aplicación de distintas herramientas digitales orientadas a este ámbito; producir una publicación de carácter periodístico a partir de la integración de los diferentes 
elementos que intervienen en esta, con especial énfasis en el capítulo visual; y aprovechar diferentes recursos tecnológicos para la difusión, potenciación y aprendizaje del mensaje gráfico.

Finalmente, la memoria de verificación cita varias competencias explícitamente asociadas a la alfabetización visual del estudiante, con alusiones directas al diseño gráfico, la cultura visual, el factor comunicacional y la tecnología; entre ellas, una competencia general particularmente significativa (capacidad y habilidad para el diseño de los aspectos formales y estéticos) y un conjunto de destrezas que explican el sentido de los contenidos y metodología adoptada: fomentar la cultura visual de los estudiantes en el ámbito del diseño gráfico; comprender los elementos fundamentales en la confección de una imagen propia del grafismo; aprender a construir productos gráficos que ayuden a una mejor comprensión del mensaje y que sean coherentes con su intención comunicativa; desarrollar habilidades de lectura de imágenes; dominar las herramientas tecnológicas necesarias en el proceso de configuración de la imagen; capacidad y habilidad para el diseño de los aspectos formales y estéticos a través de elementos gráficos e icónicos; y, finalmente, capacidad para comprender los procesos de creación de significado en la imagen del grafismo.

\section{Contenidos y sistema de evaluación}

Partiendo del anterior descriptor, los objetivos y las competencias, y atendiendo a la titulación en la que se enmarca (Periodismo) y al carácter introductorio que la define, la asignatura busca profundizar en aquellos fundamentos de diseño gráfico que pueden resultar de especial utilidad para el futuro comunicador. Se centra, por tanto, en el lenguaje visual del diseño de publicaciones frente a otras consideraciones (su producción impresa, por ejemplo). Atendiendo al área de conocimiento en la que se ubica, el programa de la materia presta, 
por tanto, una singular atención al ámbito del diseño editorial, especialidad a la que pertenecen los dos grandes proyectos de la asignatura (el diseño de revistas y de libros). Enmarcados en las denominadas metodologías activas para el desarrollo de proyectos concretos (Project Based Learning, PBL), los dos trabajos mencionados están específicamente concebidos para responder a los retos mencionados en los objetivos:

- Diseño de revista: mediante el desarrollo de 20 páginas pertenecientes a secciones previamente seleccionadas (portada, sumario, opinión, reportaje, entrevista y páginas especializadas), se hace hincapié en la construcción de la página mediante la utilidad de los diferentes elementos redaccionales; la estructuración de la superficie mediante la retícula, la jerarquía y el contraste tipográfico; el uso expresivo de la tipografía y el color; y la legibilidad.

- Diseño de una colección de libros: busca ahondar en la noción de sistema gráfico o identidad visual editorial (González, 2002), mediante el diseño de tres cubiertas (más una contracubierta), y en la legibilidad del texto base de las páginas interiores, representadas por dos capítulos como ejemplo y conformadas, preferiblemente, por textos escritos por los propios estudiantes en otras asignaturas.

Atendiendo al énfasis sobre el aprendizaje del lenguaje visual, los aspectos tecnológicos se centran en la confección y edición de la página mediante la aplicación de maquetación Adobe InDesign, obviando así otros conocimientos relativos a la producción impresa, dado que, en la materia que atañe a este estudio, este proceso se limita a su impresión virtual y su publicación en línea en el repositorio Issuu.

Los criterios de evaluación de ambas prácticas están distribuidos en tres categorías, correspondientes al empleo coherente del lenguaje visual (tipografía, 
composición y color, fundamentalmente), a la aplicación de las herramientas tecnológicas (centradas, como se ha mencionado, en el dominio de Adobe InDesign, cuyo uso está estrechamente vinculado a las competencias visuales) y a otras cuestiones de carácter general, en las que se alude explícitamente al seguimiento de una publicación real, cuyo título el alumno debe facilitar previamente al profesor.

Por su parte, debido al carácter fundamentalmente proyectual de la asignatura, la parte teórica insiste en aquellas nociones que resultan esenciales en la confección de ambos proyectos y que se organizan en cuatro capítulos: el análisis de los elementos redaccionales que intervienen en el diseño editorial; el estudio de la tipografía, que aborda cuestiones como la anatomía del tipo, las categorías tipográficas y las variantes (estilos), reglas de legibilidad y los fundamentos de contraste y jerarquía tipográficos; las claves compositivas, centradas la diagramación de la página mediante el empleo de la retícula, la jerarquía (en íntima relación con el apartado tipográfico y la noción de pesos visuales) y el aprendizaje de los principios básicos de comunicación visual (equilibrio, proporción o simplicidad, por ejemplo); y, finalmente, un último bloque que versa sobre el uso del color (funciones, dimensiones, sistemas y combinaciones cromáticas).

Siguiendo el anterior planteamiento, el sistema de evaluación parte de tres valoraciones parciales: un 35\%, derivado de pruebas teóricas tipo test sobre el contenido de los bloques citados; un 60\%, atribuido a los dos mencionados proyectos prácticos; y un 5\%, asignado a tareas complementarias, referidas básicamente a la gestión de las plataformas Pinterest e Issuu. 


\section{Metodología docente}

En relación con las actividades desarrolladas en la asignatura y su secuencialidad en el cuatrimestre, el profesor, en una primera fase del calendario y apoyado en multitud de ejemplos reales centrados en la tipología de proyectos que los alumnos deben desarrollar en la materia (revista y libro), imparte en las sesiones teóricas los fundamentos básicos del lenguaje visual en el diseño editorial; al mismo tiempo, en grupos prácticos más pequeños, explica cómo implementar los anteriores conceptos en el programa de maquetación Adobe InDesign. Al término de estas sesiones, se realizan dos pruebas tipo test sobre los bloques teóricos y un ejercicio sobre el uso de la herramienta de autoedición para garantizar el aprendizaje de estos conocimientos, que el alumno debe demostrar para superar la materia.

Una vez asimilada la base teórica y las funcionalidades de la aplicación digital, los alumnos comienzan a desarrollar el primer gran proyecto (diseño de revista); en este, partiendo de las secciones mencionadas, se exige inicialmente la adaptación estricta de las páginas de una publicación impresa real (empleada como modelo) a un nuevo contenido elaborado por el estudiante, un proceso que persigue un análisis riguroso del lenguaje visual y de sus piezas constitutivas. En un primer momento, y pese a determinadas reticencias por parte del alumnado — que lamentan un cierto encorsetamiento y falta de libertad creativa—, se solicita expresamente la reproducción exacta de las claves gráficas de estas páginas. Este procedimiento permite comprender algunos de los fundamentos sintácticos básicos: la relación jerárquica y la proporción entre elementos, la importancia de los blancos, la necesidad de atender a todos los atributos tipográficos (entre ellos, la alineación, la partición de palabras o el interlineado como algunos de los rasgos menos evidentes al principio), el propio formato y, en general, la importancia de los detalles. A medida que el alumno asume el funcionamiento y las normas básicas de 
construcción, se otorga una mayor libertad en el diseño de la página frente a la estricta representación inicial del modelo seleccionado y se permiten variaciones creativas que conducen a la progresiva personalización del trabajo.

Sobre la elección del modelo de revista, debido a la dificultad de definir objetivamente el concepto de calidad gráfica, a la heterogeneidad en la oferta del mercado editorial y a la todavía incipiente cultura visual del alumnado, se proporciona una amplia bibliografía y enlaces a algunos recursos de interés, como la relación anual de galardonados en los Premios $\tilde{\mathrm{N}} \mathrm{H}$ a los mejores trabajos de diseño periodístico. En todo caso, este proceso de selección es supervisado por el profesor.

Finalizada la confección de la revista y evaluados los trabajos, el esquema se respeta casi invariablemente en el segundo proyecto, en el que los alumnos, a partir de un concepto determinado (vinculado al contenido elegido para sus publicaciones), deben rescatar ejemplos reales que sirvan como referencia para el diseño de una colección de libros ficticia; en esta práctica, mientras se exige un seguimiento fiel de algunos atributos del modelo —el formato o los elementos de las páginas interiores (mancha, márgenes y atributos tipográficos centrados en la legibilidad, esencialmente)—, se permite una cierta libertad en la confección de las cubiertas y la contracubierta, justificada por la experiencia acumulada durante el curso. En todo caso, el estudiante debe argumentar y valorar con el profesor cualquier planteamiento gráfico ajeno al producto original. Asimismo, se proporciona una marca gráfica vectorial genérica, de una editorial también ficticia, que los estudiantes deben incorporar a la composición.

En ambos proyectos, se emplea un segundo método de inspiración, que consiste en la búsqueda de imágenes relacionadas con cada uno de los apartados teóricos de la asignatura (orientados expresamente, como se ha 
mencionado, al trabajo práctico). Las piezas se almacenan mediante la herramienta online de marcadores de imágenes Pinterest y se organizan en tableros, correspondientes a cada uno de los bloques teóricos: tipografía (categorías, estilos, contraste tipográfico), color (combinaciones cromáticas en portadas) y retículas, además de un bloque introductorio orientado a la comprensión de los distintos elementos redaccionales. Este procedimiento se estima de gran utilidad para descubrir opciones u alternativas que complementan a la publicación escogida como referencia. Las imágenes están extraídas directamente de otros productos impresos, blogs de diseño editorial, cuentas especializadas de Instagram, páginas web de premios de diseño gráfico, publicaciones de Issuu o directamente de Pinterest que, inesperadamente, propicia un interesante trabajo colaborativo mediante el intercambio de las piezas reunidas por el alumnado.

El uso combinado de los dos anteriores procesos basados en la imitación (la reproducción inicial de los modelos seleccionados y la búsqueda de imágenes en Pinterest) se considera decisivo para permitir al alumno comprender los esquemas básicos del lenguaje visual en el diseño de publicaciones y descubrir un primer catálogo de opciones para la configuración de ambos proyectos. Si el seguimiento de un modelo de referencia facilita al estudiante entender la lógica configurativa de cada publicación (revista y libro), las piezas rescatadas en Pinterest sirven para descubrir alternativas que, una vez afianzadas las nociones básicas, permiten implementar variaciones - tipográficas, cromáticas, compositivas - en el diseño original y customizar la solución visual.

Por otro lado, siguiendo la citada metodología de observación participativa, el profesor acompaña en todo momento la elaboración de ambos proyectos y analiza detalladamente con el estudiante la exactitud - y las diferencias - de la solución adoptada con respecto al modelo seleccionado, con revisiones periódicas que son imprescindibles para superar el trabajo. Asimismo, en 
una fase más avanzada, cuando los alumnos han asimilado los principios fundamentales y disponen de la pericia suficiente para introducir variaciones coherentes, se discute con ellos la pertinencia de estas aportaciones. El rigor científico del método se sustenta, así, en la exigencia indiscutible de respetar los mecanismos de imitación que, al mismo tiempo, constituyen un decisivo criterio de evaluación.

\section{Resultados}

Los resultados académicos avalan la utilidad del procedimiento de imitación en la alfabetización visual en el diseño editorial y permiten observar un elevado nivel de motivación y éxito en un grupo de estudiantes con un perfil muy heterogéneo, que muestra preferencias profesionales muy dispares (y, por tanto, un interés desigual al comienzo de la materia), un evidente desconocimiento previo del objeto de estudio y, además, importantes dificultades iniciales en el uso de aplicaciones de autoedición.

Como se observa en la Figura 1, la selección y posterior reproducción de un modelo de referencia en el primer ejercicio (diseño de revista) permiten a los estudiantes comprender la lógica conformativa y la estructura interna de la página o la coherencia en el empleo de los elementos visuales. La imitación estricta en los comienzos de cada proyecto conduce, en fases posteriores, a un mayor atrevimiento creativo, con la introducción progresiva de variaciones (frecuentemente inspiradas en los recursos almacenados en Pinterest), que evidencia una muy notable evolución general de la cultura visual del estudiante. 

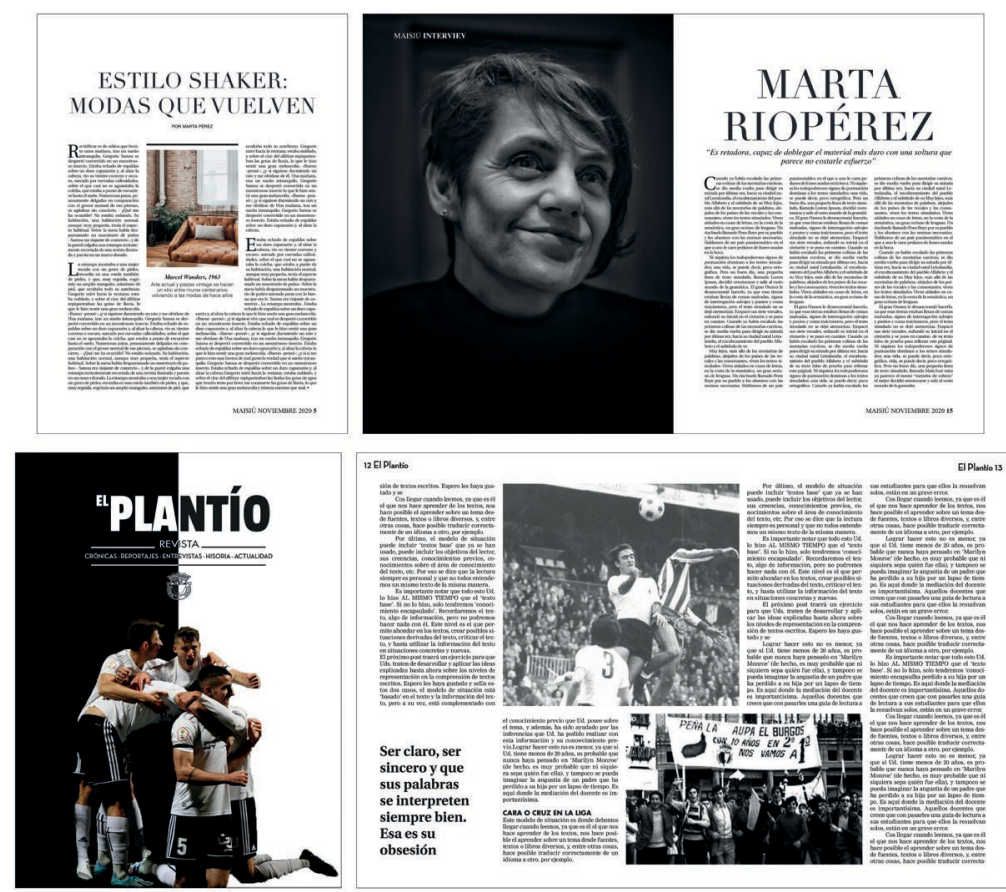

Figura 1. Diseño de páginas de revista, realizado por los estudiantes Marta Pérez Tedín (arriba) y Jorge Fernández Marijuán (abajo), inspirados en las publicaciones Vogue y Líbero/Panenka, respectivamente. Fuente: estudiantes citados y elaboración propia.

La mayor cultura visual adquirida en el primer proyecto permite suavizar las restricciones de imitación en el segundo reto (diseño de libro) y proporciona al estudiante una mayor seguridad en la inclusión de variaciones gráficas con respecto a la referencia seleccionada. Los conocimientos tipográficos y compositivos aprehendidos durante la confección de la revista contribuyen a agilizar la producción de páginas interiores — cuyo diseño está orientado específicamente a la legibilidad-y permiten, en el desarrollo de las cubiertas, 
una mayor flexibilidad para adaptarse a las imágenes rescatadas para representar el contenido (fotografías, habitualmente) y una sólida comprensión de los requisitos de un sistema visual (Figura 2).
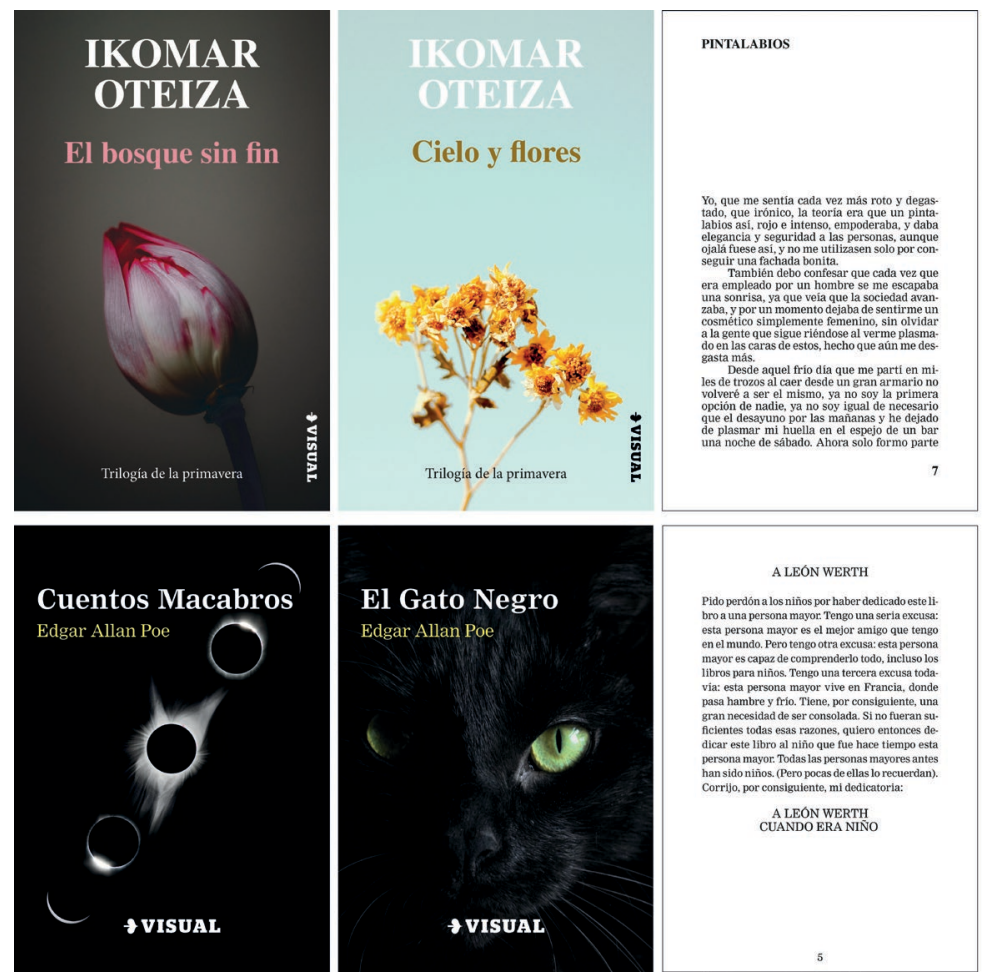

Figura 2. Diseño de sistemas de cubiertas y páginas interiores de libros, realizado por los estudiantes Ikomar Oteiza Pierola (arriba) y Guillermo Pérez Sánchez (abajo), inspirados en las colecciones Booklet (Planeta de Libros) y Alfaguara, respectivamente. Fuente: estudiantes citados y elaboración propia. 
Se observa también una interesante respuesta en el diseño de los elementos concretos de la página: el esfuerzo por reproducir con exactitud el original facilita, por ejemplo, el conocimiento de la forma tipográfica y las diferencias entre las distintas categorías, el valor de las familias con varios estilos para dinamizar la página mediante el contraste, una precisa estimación de los tamaños, la utilidad de la retícula — cuyo uso contribuye también a aumentar la comodidad en la confección- o los beneficios de una paleta cromática bien delimitada.

Como se ha mencionado, la colección de imágenes rescatadas vía Pinterest contribuye decisivamente a familiarizarse con algunos conceptos abordados en la teoría (los diferentes tipos de retícula, las alternativas en el contraste tipográfico o la anatomía de la letra mediante el análisis de las distintas categorías de familias, entre otros), cuya asimilación se intuye más costosa siguiendo otros métodos (una evaluación convencional mediante examen, por ejemplo).

Esta estrategia docente está también avalada por los excelentes resultados académicos obtenidos: de los 63 alumnos presentados a las convocatorias ordinarias de los dos últimos ejercicios (30 en el curso 2019-20 y 33 en el 2020-21), 56 alumnos superaron la asignatura (un 89\% del total, el 100\% en el primer año evaluado) y 19 (casi un tercio del total) obtuvieron una calificación de sobresaliente. Estas cifras se refuerzan con el apoyo general a la labor docente, una satisfacción que incluye una alta estimación del valor de la asignatura en la formación, con un promedio de 4,75 puntos sobre 5 . 


\section{Conclusiones}

Los resultados ponen de manifiesto la relevancia de la copia en la estrategia de alfabetización visual en diseño gráfico, un método que, como se ha demostrado, resulta de gran utilidad para fomentar la cultura visual del estudiante, especialmente en las fases más tempranas de aprendizaje: en el área editorial, debido a la necesaria atención a las normas que favorecen la transmisión eficaz del mensaje -la proporción, el equilibrio o la legibilidad tipográfica, que se plasman en criterios concretos como el cuerpo, el interlineado, la jerarquía visual o el respeto a la retícula-, este proceso de imitación se revela fundamental. Junto con estas consideraciones de carácter funcional, la imitación permite al alumno incrementar el repertorio disponible de opciones gráficas para acometer el diseño de esquemas concretos — por ejemplo, un bloque titular, un pie de foto o el texto base- $y$ del planteamiento visual de la página, globalmente.

En relación con el alcance del método, comoseha mencionado, es imprescindible concebir este proceso de imitación - en detrimento de una mayor libertad visual inicial- como un recurso especialmente interesante en las primeras etapas formativas, de cara a proporcionar al estudiante los fundamentos básicos del lenguaje del diseño gráfico; en cambio, parece aconsejable matizarlo en alumnos más experimentados, en fases más avanzadas o en otros contextos, donde la inspiración y la investigación mantienen la misma relevancia pero, en cambio, la apropiación exacta de modelos es menos decisiva y, además, podría aproximarse a mecanismos próximos al plagio. Conviene, por tanto, instruir a los estudiantes sobre el significado de este proceso. Es importante subrayar, asimismo, que el presente texto alude expresamente a las bondades de esta técnica en aquellos aspectos que afectan específicamente al lenguaje visual: no se contemplan aquí otras consideraciones (de índole conceptual, redaccional o de viabilidad empresarial) que, si bien recomiendan un exhaustivo proceso 
de investigación (benchmarking), no parecen tan apropiadas para un proceso de imitación como el que se describe. En cualquier caso, este estudio no juzga la idoneidad del método en estas competencias.

Asimismo, la experiencia docente muestra cómo, en un gran número de casos, la copia no solo permite afianzar los conocimientos sobre la parte plástica del lenguaje (en su vertiente más estética) sino que también contribuye a comprender los aspectos comunicativos y semánticos; así, el valor del factor dimensional, las connotaciones del color, la eficacia de los blancos o el valor expresivo de la forma tipográfica son aspectos que afectan directamente al significado de la página y a la propia información.

Los resultados evidencian, por otra parte, que esta técnica inicial de copia no equivale a una restricción de la creatividad, sino que proporciona unas bases sólidas de alfabetidad visual que permiten una mayor autonomía expresiva posterior. Especialmente en determinados ámbitos, como el analizado en este texto, la libertad creativa debe emerger del conocimiento profundo de sus principios más elementales (el imperativo de la legibilidad, el valor de la retícula, la utilidad del contraste tipográfico): solo comprendiendo el funcionamiento básico de cada especialidad y el porqué de determinadas decisiones pueden aportarse posteriormente variantes constructivas. Así, modificaciones tipográficas que obedecen al concepto editorial, alternativas cromáticas, variaciones escalares o la adición de elementos redaccionales son algunos cambios habituales que, una vez asumidos los principios comunicativos, son introducidos por los estudiantes con respecto a los esquemas iniciales. Superadas ciertas dudas en las primeras fases, estos comprenden finalmente el sentido de esta metodología e incluso agradecen la necesidad de respetar estos esquemas. 
Se observa también cómo, pese a las dificultades iniciales y a una común impericia del estudiante en las herramientas informáticas (Adobe InDesign, en este caso), el posterior dominio del software resulta determinante para comprender de forma más eficaz el sentido de determinados factores (la necesidad de una retícula, los matices dimensionales, el correcto uso de atributos como el interlineado o la partición de palabras) y la lógica configurativa de la página. En fases más avanzadas, la propia tecnología puede interpretarse como un recurso que facilita la creatividad, quizás por la inmediatez para visualizar los resultados o por la agilidad que proporciona al estudiante en la toma de decisiones. Junto con estas aplicaciones de autoedición, otros recursos tecnológicos (como Pinterest) se consideran de gran utilidad para incrementar la cultura visual del estudiante al facilitar la comodidad en la organización de la documentación y la recogida de información.

Por tanto, entendiendo la alfabetidad visual como el conjunto de competencias que permiten la correcta interpretación y expresión eficaz de los mensajes visuales, la excelencia que evidencian los resultados académicos en la experiencia educativa descrita muestra cómo el recurso de la imitación puede convertirse en una valiosa herramienta en la enseñanza del lenguaje visual y en el aprendizaje, por parte de los futuros diseñadores gráficos, de aquellas habilidades básicas (de lectura y creación del discurso visual) que les permitirán en un futuro afrontar con solvencia las tareas propias de la profesión. A su vez, esta alfabetización resulta imprescindible para el posterior crecimiento creativo del alumno, no solo en el terreno editorial sino también, presumiblemente, en distintas disciplinas del diseño gráfico. Por otro lado, frente a otras investigaciones anteriores relativas a este campo, la principal novedad de este artículo reside en la descripción pormenorizada de un sistema específico que utiliza satisfactoriamente la copia en el diseño gráfico como un instrumento nuclear para el aprendizaje del lenguaje visual en estudiantes noveles. El rigor científico de este método se sustenta en el seguimiento estricto 
de una técnica de observación participativa mediante la cual el profesor garantiza, en todo momento, la adopción del citado recurso de imitación y su repercusión en la construcción del mensaje visual por parte del alumnado.

Más allá de estas conclusiones, se quiere poner de manifiesto algunas limitaciones que pueden condicionar la implementación de esta metodología. En primer lugar, las características y el contexto de la materia condicionan la adopción del método: en este caso, la propia naturaleza introductoria y el esquema del plan de estudios — que incluye asignaturas más específicas en cursos superiores, como Diseño Periodístico- justifican un sacrificio inicial de la libertad creativa en favor de una mayor previsibilidad visual, orientada a la comprensión de los mecanismos básicos.

El citado énfasis de la asignatura en las habilidades introductorias de lenguaje visual frente a otras competencias (tecnologías de producción, viabilidad comercial o concepto del proyecto) explica también la idoneidad de los procesos de imitación: el método no está verificado, por tanto, en programas más avanzados o con objetivos distintos. Sin embargo, y pese a que el caso descrito se circunscribe a una materia (Comunicación Visual), una titulación (Periodismo) y una especialidad (diseño editorial) concretas, la metodología parece perfectamente exportable a otras asignaturas ligadas a distintas áreas de conocimiento o ámbitos profesionales del diseño gráfico, como la dirección de arte, el diseño de identidad visual o el diseño de interacción, por citar algunos ejemplos.

Debido a los mismos motivos planteados previamente (el carácter introductorio o la inclusión en el plan de estudios de asignaturas complementarias), la materia no contempla algunos elementos de gran peso en el diseño de publicaciones (infografía, fotografía) que se abordan en cursos posteriores. Asimismo, se prevé profundizar en esta fórmula formativa mediante el uso de nuevos recursos, como 
Instagram, una red social que ya ha sido utilizada con éxito en otras materias también vinculadas al diseño gráfico. En investigaciones futuras, por último, pese a que las evaluaciones docentes y los resultados académicos evidencian los beneficios de la imitación como estrategia de aprendizaje, parece oportuno completar el estudio con entrevistas a los alumnos participantes para reforzar el método empleado y respaldar las conclusiones.

\section{Referencias}

Abdulla, J. (7 de enero de 2021). Against Performative Positivity. Futuress. https://futuress.org/ magazine/against-performative-positivity

Aparici, R. y García-Matilla, A. (1998). Lectura de imágenes. Ediciones de la Torre.

Arfuch, L., Chaves, N. y Ledesma, M. (1997). Diseño y comunicación. Teorías y enfoques científicos. Paidós.

Barba, M. N. y Palacios, E. P. (2018). Las redes sociales en el contexto académico universitario. Desafíos al docente. Etic@net: Revista científica electrónica de Educación y Comunicación en la Sociedad del Conocimiento, 18(1), 83-101. https://dialnet.unirioja.es/descarga/ articulo/6531559.pdf

Bastías, R. (2020). Alfabetización en Diseño. Una Experiencia de Diseño Participativo con Adultos Mayores de Escasos Recursos. Creación y pensamiento, 4(8), 77-92. https://doi. org/10.5354/0719-837x.2020.57653

Bridges, A. (2020). Competencies and tools of higher education graphic communications programs. Journal of Print and Media Technology Research, 4, 243-254. https://doi. org/10.14622/JPMTR-2011

Cabero-Almerara, J., Del Prete, A. y Arancibia, M. L. (2019). Percepciones de estudiantes universitarios chilenos sobre uso de redes sociales y trabajo colaborativo RIED. Revista Iberoamericana de Educación a Distancia, 22(2), 35-55. http://dx.doi.org/10.5944/ ried.22.2.22847

Campi, I. (2020). ¿Qué es el diseño? Gustavo Gili. 
Cerezo, J. M. (2017). Diseñadores en la nebulosa. El diseño gráfico en la era digital (2a ed.). Campgràfic.

Colás-Bravo, M. P., Conde-Jiménez, J. y Martín, A. (2015). Las redes sociales en la enseñanza universitaria: aprovechamiento didáctico del capital social e intelectual. Revista Interuniversitaria de Formación del Profesorado, 83, 105-116. https://www.redalyc.org/ pdf/274/27443659008.pdf

Contreras, F. R. (2019). Estudio filosófico sobre la mirada estética en el diseño. Kepes, 16(19), 11-38. https://doi.org/10.17151/kepes.2019.16.19.2

Danesi, M. (2017). The semiotics of emoji. Bloomsbury.

De la Flor, F. R. (2009). Giro visual. Editorial Delirio.

Díaz, C. (1993). Alfabeto gráfico, alfabetización visual (desarrollo creativo cognitivo). Ediciones de la Torre.

Dondis, D. A. (1998). La sintaxis de la imagen: introducción al alfabeto visual (13 ${ }^{\text {a }}$ ed.). Gustavo Gili.

Entenza, A., Tena, D. y Martínez, J. M. (2015). Creatividad y Tecnología. Influencias mutuas para un enfoque docente. Grafica, 3(5), 55-60. https://doi.org/10.5565/rev/grafica.29

Fontana, R. (2019). La palabra, la letra y la página. La forma gráfica del diseño. Campgràfic.

Frascara, J. (2018). Enseñando diseño. Infinito.

Gamonal, R. (2012). Del boceto al diseño: la materialización del discurso visual en el diseño gráfico. Vivat Academia, 119, 42-57. https://doi.org/10.15178/va.2012.119.42-57

Gamonal, R., Mena, S. y Martínez, S. (2020). Periodismo y Diseño: Diseñar es informar. En J. Sotelo y S. Martínez (Coords.), Periodismo y Nuevos Medios: Perspectivas y Retos (pp. 5369). Gedisa.

Gómez, B., Esteban, S. y Vargas, P. (2018). Pinterest e imagen como herramientas de apoyo a la enseñanza universitaria. Diseño de una rúbrica de evaluación. En R. Roig-Vila (Coord.), Redes de Investigación en Docencia Universitaria, 18 (pp. 275-283). Universidad de Alicante.

González, J. (2002). Identidad Visual Corporativa. La imagen de nuestro tiempo. Síntesis. 
González-Díez, L., Puebla-Martínez, B. y Pérez-Cuadrado, P. (2018). De la maquetación a la narrativa transmedia: una revisión del concepto de "diseño de la información periodística". Palabra Clave, 21(2), 445-468. https://doi.org/10.5294/pacla.2018.21.2.8

González-Mardones, S. (2016). El diseño gráfico y sus profesionales. Retos y definiciones (tesis doctoral). Universitat de Barcelona, Barcelona.

Gràffica. (2016a). "Lo que falta en las escuelas y en los alumnos es la crítica y la autocrítica". Gràffica, 3, 63-65.

Gràffica. (2016b). Sobre la creatividad. Gràffica, 4, 39-74.

Gràffica. (2020). ¿El mejor método creativo? El tuyo. Gràffica, 18, 123-125.

Heller, S. y Anderson, G. (2016). El libro de ideas para el diseño gráfico. Blume.

Jiménez-Narros, C. (2016). Proyectos y resultados de aprendizaje en las materias de diseño gráfico de la Universidad Nebrija. En Padilla Castillo, G. (Coord.), Aulas virtuales: Fórmulas y prácticas, 273-284. Madrid: McGraw Hill.

Kędra, J. (2018). What does it mean to be visually literate? Examination of visual literacy definitions in a context of higher education. Journal of Visual Literacy, 37(2), 67-84. https:// doi.org/10.1080/1051144X.2018.1492234

Kędra, J., \& Žakevičiūtė, R. (2019). Visual literacy practices in higher education: what, why and how? Journal of Visual Literacy, 38(1-2), 1-7. https://doi.org/10.1080/105114 4X.2019.1580438.

Kleon, A. (2012). Roba como un artista. Las 10 cosas que nadie te ha dicho acerca de ser creativo. Gustavo Gili.

Knight, C. y Glaser, J. (2010). Ejercicios de diseño gráfico. Gustavo Gili.

Lessig, L. (2016). Leyes que ahogan la creatividad. Gràffica, 4, 30-32.

López, R. y Villa, G. (2017). El aula de diseño como escenario de exploración entre alfabetidad visual y pensamiento crítico. Kepes, 14(15), 173-194. https://doi.org/10.17151/ kepes.2017.14.15.7

Mazzeo, C. (2015). ¿Qué dice del diseño la enseñanza del diseño? Infinito.

Mazzeo, C. (2017). Diseño y sistema. Bajo la punta del iceberg. Infinito. 
Millman, D. (2009). Los principios básicos del diseño gráfico. Blume.

Morales, A. y González, E. (2021). Interdisciplinariedad en la formación universitaria del diseño gráfico: entre la teoría y la práctica. Educación, 30(58), 228-249. https://doi.org/10.18800/ educacion.202101.011

Ortega, J. A. (2011). Publicidad e iconicidad. Propuestas para una metodología de Alfabetización Visual. En VV.AA., Publicidad, educación y nuevas tecnologías (pp. 200-322). Ministerio de Educación y Ciencia.

Peltzer, G. (1991). Periodismo iconográfico. Ediciones Rialp.

Presol-Herrero, Á. y Pérez-Manzanares, J. (2020). La necesidad de educación estética para la formación en diseño gráfico: una propuesta metodológica. Vivat Academia, 153, 117-136. https://doi.org/10.15178/va.2020.153.117-136

Puebla-Martínez, B., González-Díez, L. y Pérez-Cuadrado, P. (2018). La estética apresurada de "El Debate" preherreriano 1910-1911: Un estudio sobre la gráfica del diario católico antes de la llegada de Ángel Herrera. Historia y comunicación social, 23(2), 405-424. http:// dx.doi.org/10.5209/HICS.62265

Rambla, W. (2007). Estética y diseño. Ediciones Universidad de Salamanca.

Ramírez, M. F. (2020). Prácticas de visualización en la investigación académica en diseño gráfico. Kepes, 17(2), 77-108. https://doi.org/10.17151/kepes.2020.17.22.4

Rodríguez-Sandoval, E., Vargas-Solano, É. y Luna-Cortés, J. (2010). Evaluación de la estrategia "aprendizaje basado en proyectos". Educación y Educadores, 13(1), 13-25. http://www. redalyc.org/articulo.oa?id=83416264002

Salehudin, M., Hamid, A., Zakaria, Z., \& Yunus, M. (2020). Instagram User Experience in Learning Graphic Design. International Journal of Interactive Mobile Technologies, 14(11), 183-199. https://doi.org/10.3991/ijim.v14i11.13453

Shaughnessy, A. (2006). Cómo ser diseñador gráfico sin perder el alma (2ª ed.). Index Book.

Suárez-Carballo, F. (2008). Fundamentos del diseño periodístico: claves para interpretar el lenguaje visual del diario. Eunsa.

Suárez-Carballo, F. (2020). La enseñanza del diseño gráfico en los grados españoles vinculados a la comunicación publicitaria: perfil del profesorado, métodos docentes y competencias tecnológicas. Grafica, 8(15), 33-42. https://doi.org/10.5565/rev/grafica.170 
Suárez-Carballo, F., Martins, N. y Martín-Sanromán, J. R. (2021). La educación estética del director de arte en los grados universitarios de Publicidad en España. Revista ICONO 14, 19(2), 143-166. https://doi.org/10.7195/ri14.v19i2.1664

Suárez-Carballo, F. y Muñiz-Velázquez, J. A. (2008). Creatividad, inspiración, copia. En C. M. Alonso (Ed.), Las fuentes de la creatividad publicitaria (pp. 111-128). Ediciones Universidad Pontificia de Salamanca.

Tavin, K. (2009). Seeing and being seen: Teaching visual culture to (mostly) non-art education students. The International Journal of Arts Education, 7(2), 14-22. https://ed.arte.gov.tw/ uploadfile/periodical/2436_00010022.pdf

Tena, D. (2004). Diseño gráfico y comunicación. Pearson Educación.

Universidad Pontificia de Salamanca (2020). Guía académica de la asignatura Comunicación visual. https://drupal.upsa.es/sites/default/files/2021_22_GD_COMUNICACION_VISUAL_1_ PER_1S.pdf

Valdés de León, G. A. (2012). De la "Alfabetidad Visual" a la Semiótica. Otra aproximación al "Lenguaje" Visual. Cuadernos del Centro de Estudios de Diseño y Comunicación, 39, 5769. https://fido.palermo.edu/servicios_dyc/publicacionesdc/archivos/346_libro.pdf

White, K. (2014). 101 cosas que aprendí en la escuela de arte. Gustavo Gili.

Zeegen, L. (2013). Principios de ilustración (2 ${ }^{\mathrm{a}}$ ed.). Gustavo Gili.

Cómo citar: Suárez-Carballo, F., Martín-Sanromán, J.-R. y Martins, N. (2022). La imitación como estrategia de alfabetización visual en la formación del diseñador gráfico. Una propuesta metodológica desde el diseño editorial. Revista KEPES, 19(25), 499-530. https://doi.org/10.17151/kepes.2022.19.25.17 